\title{
СЕМАНТИЧЕСКИЕ ШКАЛЫ: АНАЛИЗ САКРАЛЬНО-ПРОФАННОГО ЗОНИРОВАНИЯ КУЛЬТУРНОГО ЛАНДШАФТА ГОРОДА (НА ПРИМЕРЕ Г. САРАТОВ)
}

\section{SEMANTIC SCALES: ANALYSIS OF SACRAL-PROFANE ZONING CULTURAL LANDSCAPE OF THE CITY (ON THE EXAMPLE OF CITY SARATOV)}

\section{T. Kulichenko}

Summary: The process of formation of the cultural landscape of the city of Saratov is considered using axiological and structural-semiotic approaches in the analysis of semiotic texts, the understanding of which includes the structural organization of the conditional model of the city "frame - fabric - plasma». The results of the analysis made it possible to visualize the model and identify sacral-profane zoning in its structure using the developed system of semantic scales. The proposed method of analysis can serve as a tool in the humanization of the cultural landscape both at the level of theoretical research and at the level of design and aesthetic activity.

Keywords: cultural landscape of the city of Saratov; axiological approach; structural-semiotic approach; semiotic body; archetype; semiotic text; visualization; semantic scales; sacred; profane; humanization.

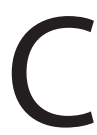
овременный городской культурный ландшафт перенасыщен информацией и цифровизированным пространством. С точки зрения технологий, цифровая трансформация городов основана на нескольких ключевых направлениях развития сферы информационных технологий - социальные коммуникации, большие данные и предсказательная аналитика, облачные технологии, искусственный интеллект, мобильность, «интернет вещей», технологии обеспечения кибербезопасности, цифровые платформы.

В то время, как комфортный для проживания человека «умный» город, должен отвечать целому ряду требований: самое главное - понимать, что город предназначен, прежде всего, для горожанина, его удобной и безопасной жизнедеятельности, направленной прежде всего на достижение личных возможностей, интересов и ценностей в профессиональной, досуговой и бытовой сферах. Каждому городу присущи свои идентичные признаки, идентификационные черты и образные характеристики, хотя процессы современного общества стремительно стирают эту идентичность. Человек в приоритете, всё остальное - вторично и на любом этапе трансфор-
Куличенко Татьяна Васильевна

Доцент, Саратовский Государственный Технический Университет имени Ю.А. Гагарина archi_tk@mail.ru

Аннотация: Рассмотрен процесс формирования культурного ландшафта города Саратов с использованием аксиологического и структурно-семиотического подходов в анализе семиотических текстов, в понимание которых включена структурная организация условной модели города «каркас ткань - плазма». Результаты анализа позволили выполнить визуализацию модели и выявление сакрально-профанного зонирования в её структуре при помощи разработанной системы семантических шкал. Предложенная методика анализа может служить инструментом в гуманизации культурного ландшафта как на уровне теоретических исследований, так и на уровне проектно-эстетической деятельности.

Ключевые слова: культурный ландшафт города Саратов, аксиологический подход, структурно-семиотический подход, семиотическое тело, архетип, семиотический текст, визуализация, семантические шкалы, сакральное, профанное, гуманизация.

мации необходим комплекс мероприятий по гуманизации культурного ландшафта, одним из которых является предложенный нами метод семантических шкал.

Учитывая факт «расширения культурного поля жизни, порождения новых смыслообразующих центров, изменения образа мышления и шкалы приоритетов», [1, с.4] выявление принципа формирования новых приоритетов общества требует рассмотрения образа жизни современного человека с точки зрения аксиологического подхода, где также необходимо учитывать общие и индивидуальные для каждой из социальных групп характеристики.

При анализе современного пространства культуры общими характеристиками для любого человека, любой этнической и социальной принадлежности является активная динамика ритма жизни в пространстве и времени и, соответственно, необходимость обеспечения психологического, эргономического и эстетического комфорта в быстро сменяющихся внешних условиях «жизненного сценария». Данные признаки применимы к обществу XXI века в целом и формируют образ жизни 
информационного общества и человека, в частности.

Вектором исследования в данном анализе является выявление характера трансформации сакрально-профанных зон архетипического основания города как на ментальном уровне, так и на уровне реально существующих пространств.

Предлагаемые семантические шкалы основаны на принципе семантического дифференциала и призваны выявить характер взаимосвязи и трансформации в процессе развития исследуемой структуры одной из базовых онтологических оппозиций - «сакральноепрофанное», которая является базовой для любой семантической структуры. Сакральное и профаническое наряду с дискретным-контлинуальным и имманентным-трансцендентным выступает инвариантным структурным фундаментом всякой семантической структуры в культуре, генетически производным от первоначальной метаоппозиции «я - другое» [5].

Кроме этой базовой оппозиции, нами рассматривается оппозиция «антропоморфное - космогоническое» в рамках смены парадигмы мышления в системе «человек-среда» изучаемого культурного ландшафта, поскольку в основе семантики любого градостроительного образования она является фундаментальной. С данных позиций соотношение этой оппозиции нами понимается и визуализируется как роль и место человека в мировосприятии.

А.В. Иконников предполагает, что фундаментальную основу архитек-турных языков и ценностных предпочтений состав ᄀляет система архетипов, сложившихся в до-языковый период из коллективного бессознательного (по Юнгу), закрепленная в мифах и пространственных формах рулкотворной среды [2]. Архетипы определяют строение арлхитектурного пространства и несут в себе культурные значения, отражающие ценностные установки людей, их экзистенциальную позицию. При этом автор разлилчает символику антропоморфных (очеловеченных) арлхетипов и сменяющих их по мере развития земледелия и усложнения общественных структур космогонических (небесных) архетипов.

«Космогонические мифы» - мифы о творении, мифы о происхождении космоса из хаоса, основной начальный сюжет большинства мифологий. Начинаются с описания хаоса (пустоты), отсутствия порядка во вселенной, взаимодействия изначальных стихий. Служат для объяснения происхождения «мира и жизни на Земле» [3].

Антропогонические мифы - мифы о происхождении (сотворении) человека (первочеловека), мифических первопредков народа, первой человеческой пары и т. п., составная часть космогонических мифов [4].

Взаимодействие сакрального и профанного в культуре мало исследовано. Сакральное и профанное - термины, имеющие универсальное применение в разных дисциплинах: философии, социологии, религиоведении, теологии, психологии. Долгое время они употреблялись в контексте других понятий и четко не выделялись для отдельного изучения. Между тем, вычленение из контекста и специальное рассмотрение сакрального и профанного (иными словами оппозиции священного и мирского, божественного и мирского) позволяет по-новому взглянуть на процессы, происходящие в человеческом обществе. Более точно понять возникновение и функционирование таких социальных феноменов как миф, религия, идеология, которые являются фундаментальными и базовыми по отношению ко всей совокупности феноменов социума. Рассмотрение заявленных феноменов поможет выявить, различить и четко проанализировать основные социальные и мировоззренческие формы воплощения сакрального и профанного, их взаимопревращения, чего ранее сделано не было из-за сложности вычленения и разделения этого во многом синкретичного феномена. Учитывая, что данные аспекты оказывают постоянное воздействие на социум (и на отдельного человека) в таких его важнейших аспектах как власть, мировоззрение и менталитет, а значит и поведение людей, можно четко заявить об актуальности заявленной темы [5].

В оценке характера сакральности или профанности, их соотношения в системе ценностей общества определяющую роль играет взаимоотношения человека и среды, понимаемой в самых различных смыслах (социокультурной, общественной, жилой, материальной и т.д.). Функционирование этой системы в зависимости от исторических, социокультурных и прочих условий, протекает по- разному с точки зрения места и роли в ней человека.

Так, в определённые периоды развития человечества образ человека можно описать различными терминами - человек-герой (Древняя Греция, Возрождение), человек-титан (XX век), человек-песчинка (Др. Египет) и т.д. Применение таких терминов «масштабирования» визуализирует столь сложную смысловую конструкцию как сакрально-профанные отношения. В такой форме подачи информации этот предельно абстрактный смысл становится доступным для восприятия абсолютно всеми. Самый первый и наиболее точный уровень восприятия в этом случае - ассоциативный, который «схватывает» информацию в форме визуального сопоставления с базовыми образами подсознания - с базовыми архетипами, используя при этом маркеры масштабирования. Следовательно, если такой подход позволяет визуали- 
зировать «масштаб» какого-либо образа, то возможно и масштабное сопоставление таких образов между собой. Именно этот феномен послужил для нас основанием использования его в качестве основного принципа семантических шкал.

Предлагаемая система семантических шкал основана на принципе визуализации предельно абстрактных понятий при помощи условных пространственно-временных границ и принципа масштабирования - апелляции к базовым архетипам пространственности. В этом аспекте временной параметр обозначен хронологическим течением «событий» по горизонтали, а пространственный - В трёх измерениях высоты, ширины и глубины.

В структурной организации шкал отсутствуют промежуточные градации, кроме того «шага», который условно обозначает границы и нулевую точку перехода «1 - 0 - 1». Это обусловлено тем, что в границах данных исследований в первую очередь имеет значение транс- формация сакрально-профанных отношений в хронологической последовательности их промежуточных состояний.

В обозначении смысловых границ шкал определяющей является система человек - среда, где человек обозначен нами как маркер масштабирования, а среда как пространство бытия сакрально-профанных ценностей.

И в профанной, и в сакральной шкале границы имеют значения: плюса в верхней части и минуса в нижней границе.

Оценка системы «человек - среда» в границах оппозиции «сакральное профанное» нами выполнена на примере культурного ландшафта города Саратов. Предварительный анализ в данном аспекте позволил выявить три основных цикла развития в данных границах и определить значения границ и условной высоты шкал.

A)
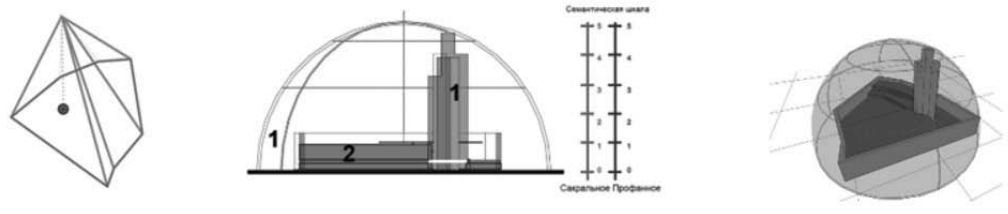

Б)
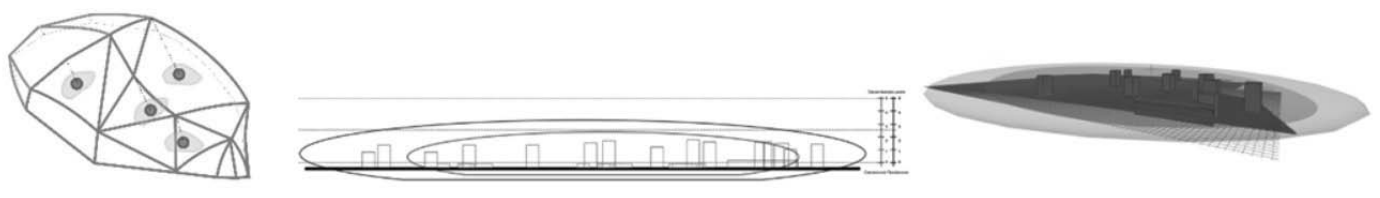

B)
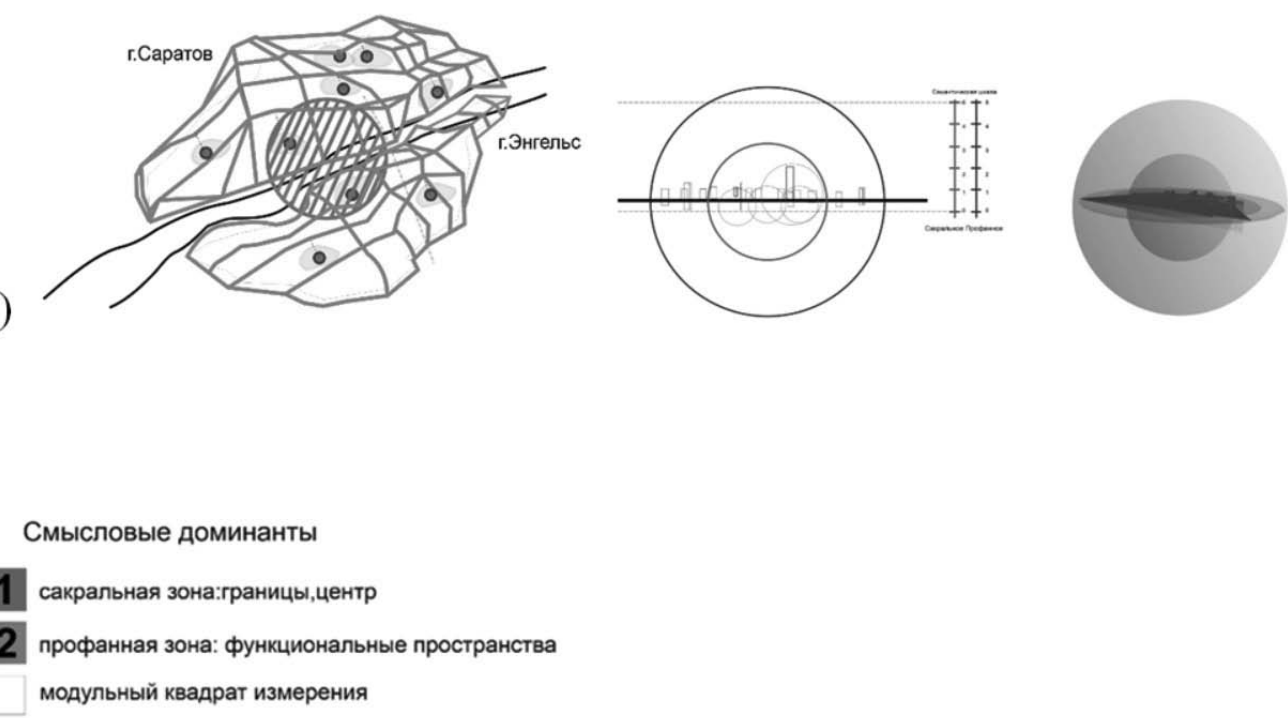

Рис. 1. Масштабирование смысловых доминант архитектурного пространства культурного ландшафта в границах оппозиции сакральное-профанное: а - первый цикл (1590 г.- 1650 г.); б) - второй цикл (1650 г. - 1750 г.); в) - третий цикл (1750 г. - 1890 г.). 
За основу в обозначении «высот» семантического пространства культурного ландшафта нами определено условное соотношение значимости архитектурных объектов как смысловых доминант в границах обозначенной оппозиции. Для осуществления данного анализа выполнено предварительное моделирование семантического тела культурного ландшафта на каждом из этапов его формирования (рис. 1. А, Б, В)

Так, в данном контексте профанная оппозиция обозначена такими границами как «Производственная среда - жилая среда», где производственная среда является высшей точкой проявления профанного и выполняет функцию верхней границы, а жилая среда - наименьшей формой выражения профанного, так как границы личного пространства для человека всегда являются сакральными границами профанного пространства.

В рамках сакральной шкалы храмовая среда обозначает высшую точку сакральности как для общественной среды, так и для личной. Светская среда в обозначении шкалы фиксирует низшую степень божественной сакральности, перетекающей в сферу «бытовой» духовности. Нулевой (или центральной) точкой в условном делении шкал является общественная среда, где вектора крайних точек сакрально-профанных отношений, стремясь к нулю, гасят друг друга (рис. 2).

Организованная таким образом система семантических шкал позволила визуализировать процесс трансформации содержания сакрально-профанных ценностей в культурном ландшафте города Саратов в хронологических границах с 1590 г. по 1890 г. и с опорой на анализ архитектурной среды. В анализе архитектурной среды ориентирами в определении смысловых доминант семиосферы и, соответственно, соотношением сакрального - профанного культурного пространства служили соотношения храмовых, светских, производственных и жилых сооружений. Данные соотношения коррелировались с господствующими моделями общественного мировосприятия на каждом из исследуемых периодов.

Так, анализ процесса трансформации сакральных ценностей на протяжении исследуемых периодов продемонстрировал изменения не только условных пространственных, но и содержательных характеристик (рис 3).

Эти изменения можно описать как вымещение господствующего в первом периоде космогонического начала из сферы сакрального в сферу профанного. Этот процесс протекал поэтапно. Первый цикл формирования культурного ландшафта характеризуется доминированием сакрального в архитектурной среде по условной (сакральные высоты в теле семиосферы) и реальной высоте сакральных объектов (храмовые сооружения). Данный период характеризуется доминированием космогонического мировоззрения.

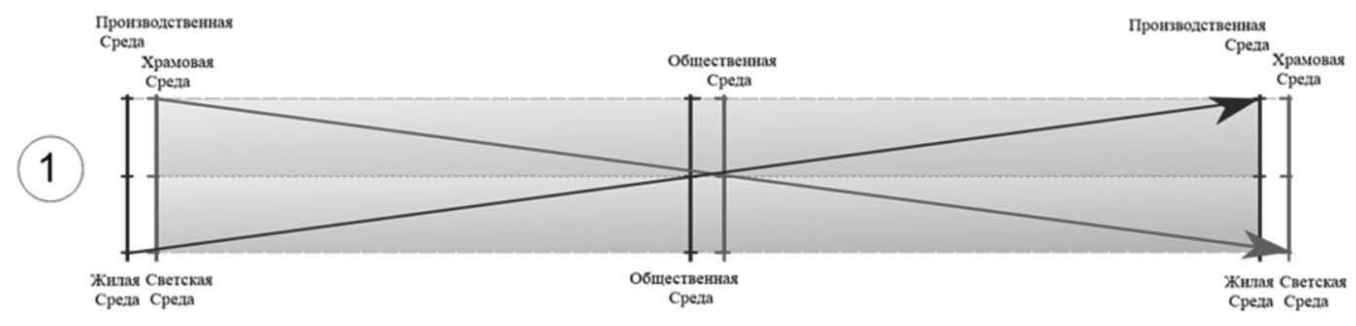

I цикл

II цик.л

\section{III цикл}

Рис. 2. Условная модель семантических шкал в границах оппозиции сакральное-профанное

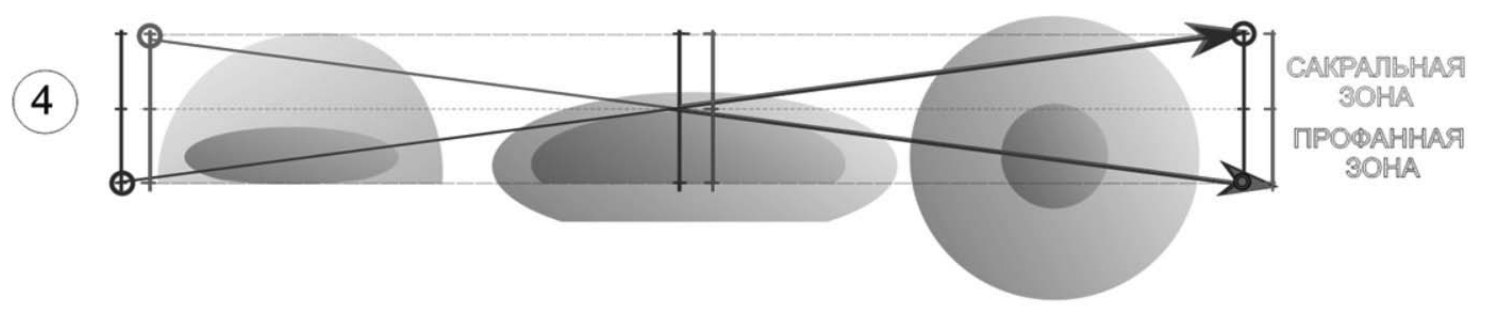
І цикл
II цикл
III цикл

Рис. 3. Процесс трансформации сакрально-профанных зон семиотического тела культурного ландшафта г. Саратов 
На втором этапе происходит сближение зон по сакрально-профанной значимости, которое выражается в дроблении сакрального пространства архитектурной среды на храмовые и светские объекты, и в разрастании и слиянии профанных зон.

Завершающий этап в структурном анализе трансформации семиотического тела культурного ландшафта представлен сжатием сакральной зоны в ядро и расширением профанной зоны до верхних границ, обозначающих уровень сакральности.

Условным «маркером масштаба» в соизмерении шкал служит модель Человека в виде условной фигуры, изменения параметров которого визуализируют характер изменения образа человека, его места и роли в сакрально-профанных отношениях в тот или иной временной период (рис 4).

Помещённая в систему семантических шкал условная модель человека позволяет сформулировать ментальную модель масштабирования в системе «человек-среда».

Так, в первом цикле сакральные ценности максимально доминируют и транслируют космогонические мифы. Профанные ценности (или антропоморфное начало) в масштабном изображении находятся на нуле и заключаются в обыденном - в обеспечении процессов ежедневного бытия. Обеспечение безопасности городакрепости, осуществляемое за счёт оборонительных стен и сооружений, относится к сакральным ценностям. В данных отношениях сакрально-профанного и антропоморфно-космогонического образ человека представляет собой образ «человека-воина».

Второй цикл визуализирует сближение сакральнопрофанных начал и концентрацию в сфере общественной среды как пространства с равной значимостью космогонического и антропоморфного мировоззрения, проявляющееся в доминировании общественных и жилых сооружений, пространств. Развитие научно-технического прогресса привело к трансмутации содержательной части сакрального и его перемещения из зоны храмовых сооружений архитектурной среды в сферу производственной и жилой. Образ человека в условном масштабировании семантических шкал обозначен как человек производственный.

Третий период визуализирован как всё то же соотношение сакрально-профанного, но их содержание качественно изменилось - сакральным становится антропоморфное начало, а космогоническое - призвано обеспечить иные семантические начала. Доминирование в пространстве культуры цифровой виртуальной реальности принципиально изменило качественные характеристики сакрально-профанных отношений и образ человека в этой системе. Так в зоне сакрального находятся не столько сам человек, сколько его потребности в обеспечении комфорта в условиях виртуальной реальности. В данных условиях теряют значение прежние доминанты и это проявляется в архитектурной среде, визуализирующей ценностные ориентиры общества. Материальное пространство бытия города на данном этапе представляет собой пёструю картину разновременных пластов, разнообразных форм и смещение акцентов с формы на изменчивость содержания. Причём восприятие содержания в динамичном контексте, когда главное значение имеет постоянное движение.

Прежние сакральные ценности уходят в глубь семиотического тела, формируя его ядро, которое окружено профанной средой, расширяющейся до условных границ сакральной зоны. Сакральное ядро, находясь в профанной зоне, хранит космогоническое начало, выполняя роль архетипического основания. Потребности современного человека и общества выносят на поверхность семиотического тела антропоморфное начало и моделируют профанную зону, выросшую до масштаба сакральной сферы. Образ человека вырастает до масштабов условной модели «человек интеллектуальный», где внутреннее содержание доминирует над внешней формой и подавляет её значимость. Интеллект претендует на самостоятельное значение, теряя идентификационные признаки личности конкретного человека и сливаясь в единое с искусственным интеллектом информационное облако. Он становится коллективным интеллектом, кол-

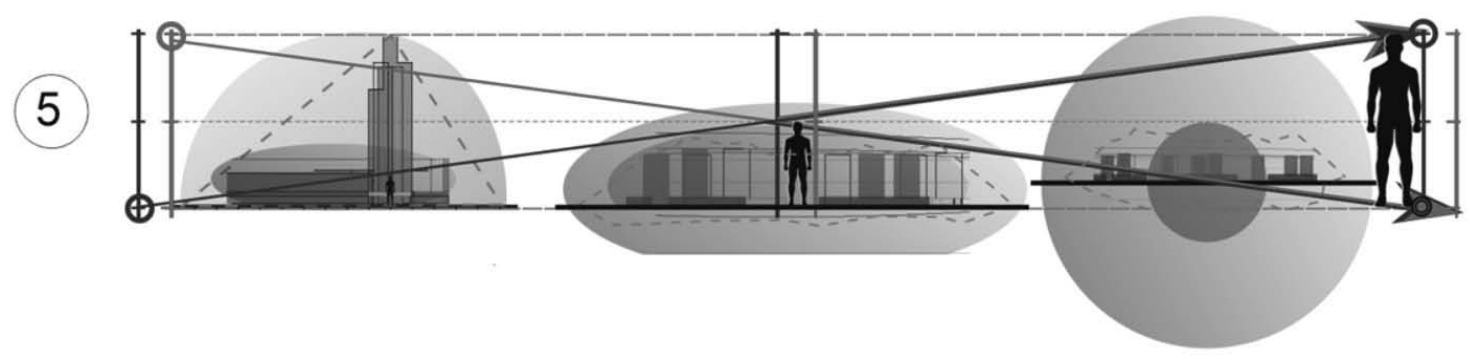

Рис. 4. Образ человека в границах сакрально-профанного: «Человек-воин» в І-ом цикле, «Человек- индустриальный» во II-ом цикле и «Человек- интеллектуальный» в III-ем цикле 
лективным разумом, высшей сакральной ценностью.

Выявленные тенденции в формировании сакральнопрофанного зониирования культурного ландшафта г. Саратов во многом являются частью общемировых процессов, но всё же, соответствуют идентификационным признакам прамодели исследуемого ландшафта. Данный подход к исследованию семиосферы города позволил определить не только общие тенденции, но и, благодаря моделированию семиотического тела, выявить конкретные пространственные координаты сакральных и профанных зон. Обозначение такого зонирования позволит выполнить ряд конкретных мероприятий по гуманизации культурного ландшафта.
В целом использование предлагаемой системы семантических шкал и методики «масштабирования» может быть полезной не только в исследованиях, направленных на архетипическую прамодель пространства культурного ландшафта, но и в более частных и узких проявлениях этого процесса.

Таким образом, метод с использованием семантических шкал может послужить основой для формирования нового вектора культурологических исследований в сфере гармонизации и гуманизации системы человексреда, а также в практических мероприятиях по выявлению профанно-сакральных зон и их гармонизации в границах архитектурного пространства.

\section{ЛИТЕРАТУРА}

1. Александрова Л.Д. Культура Виртуальной коммуникации: Автореф. дис. канд. филос. наук — Челябинск, 2009. — 26 c.

2. Иконников А.В. Художественный язык архитектуры. - М.: Искусство, 1985. - 175 С.

3. Кассирер э. Философия символических форм. Т. 2. Мифологическое мышление. - М.; СПб.: Университетская книга, 2001. - 280 с.

4. Лосев А.Ф. Знак, символ, миф. - М., 1982. - 245 с.

5. Таранова Т.Н. Генезис, онтологический статус, сущность, структура и функции аксиосферы культуры [Электронный ресурс]. - Режим доступа: https://superinf.ru/view_helpstud.php?id=2924 (дата обращения: 29.11.21)

6. Федоровских А.А. Трансформация сакрального и профанного в обществе: миф-религия-идеология: дис. ... канд. филос. наук. — Екатеринбург, 2000. - $142 \mathrm{c}$.

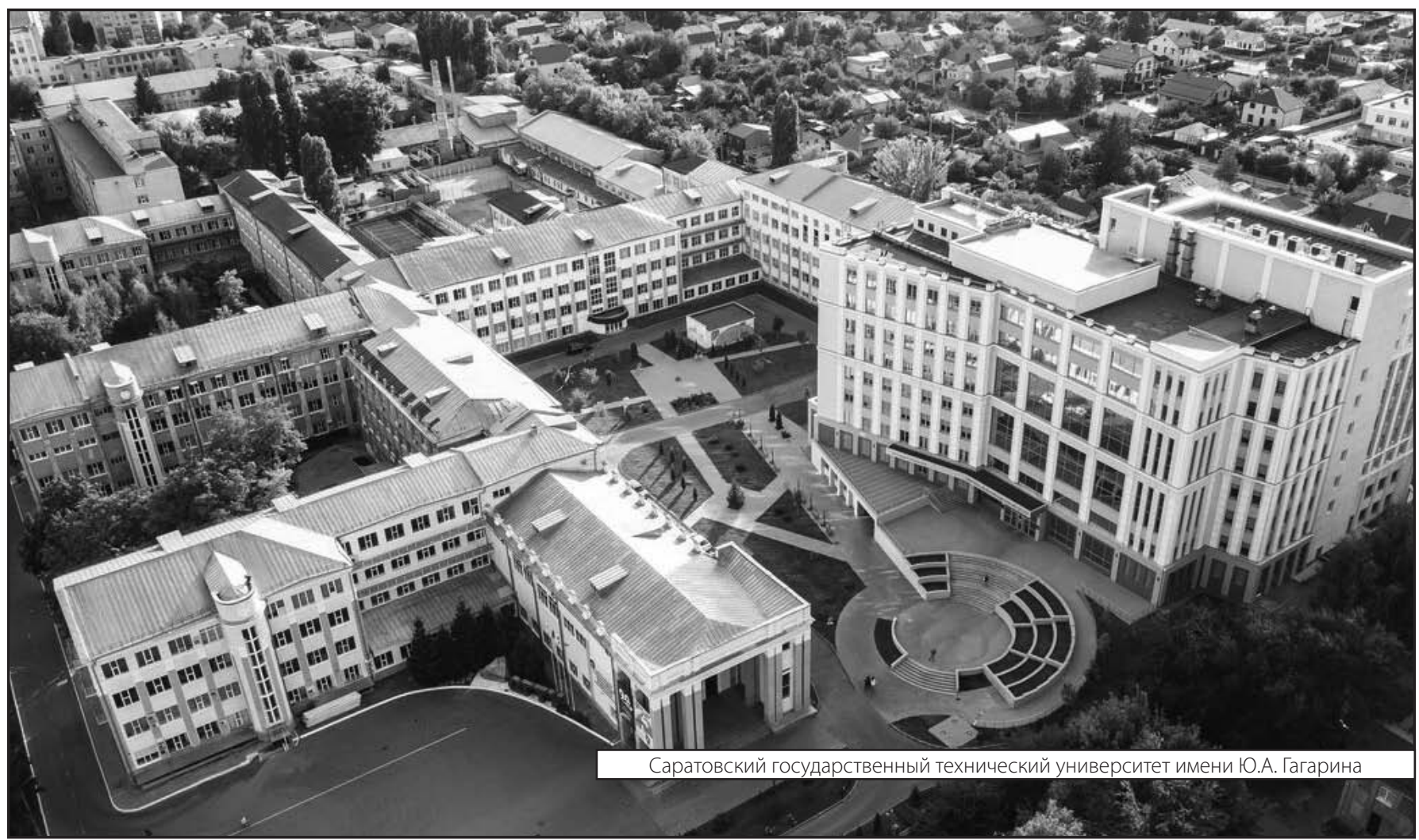

